\title{
A massive retroperitoneal neuroblastoma with stenosis of the inferior vena cava in a 5-month-old boy
}

\author{
Jui-Ting Li, ${ }^{1}$ Yang-Hong Dai, ${ }^{2}$ Shih-Ming Kuo ${ }^{1}$
}

${ }^{1}$ Department of Paediatric Surgery, Tri-Service General Hospital, Taipei, Taiwan ${ }^{2}$ Tri-Service General Hospital, Taipei, Taiwan

\section{Correspondence to} Shih-Ming Kuo, he165076373@hotmail.com

Accepted 5 March 2014

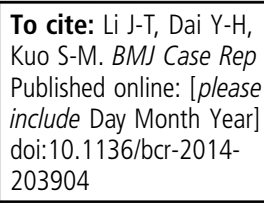

\section{SUMMARY}

Neuroblastoma is the second most common retroperitoneal tumour in children after Wilms' tumour. When it originates in the retroperitoneum, neuroblastoma usually presents as an abdominal mass with clinical manifestations of nausea, vomiting and weight loss. Imaging studies of this tumour demonstrate a heterogeneous mass with an irregular capsule and visible calcifications. Encasement and compression of the abdominal vessels, especially the inferior vena cava, are often observed. However, stenosis of the inferior vena cava has never been reported to be associated with this tumour. Here, we present a case of a 5-month-old boy with a right retroperitoneal tumour with extensive encasement of the inferior vena cava and significant narrowing of its distal part between the venous bifurcation and the tumour capsule. To our knowledge, this is the first case of neuroblastoma with this manifestation in a child.

\section{BACKGROUND}

Neuroblastoma is the second most common retroperitoneal tumour in children after Wilms' tumour. Vascular encasement with or without luminal compression is a common finding in neuroblastoma. However, vascular stenosis in the absence of external compression may be found secondary to elongation in this tumour. Once the tumour has sufficiently enlarged and the inferior vena cava (IVC) has been elongated and narrowed, thromboembolic events may occur. Therefore, this phenomenon should be considered during evaluation of the surgical risks of removing a retroperitoneal neuroblastoma.

\section{CASE PRESENTATION}

A 5-month-old Taiwanese boy was referred to our paediatric emergency department due to a palpable abdominal mass identified by his father. Several days before presentation, poor appetite was the only manifestation. There were no inherited disorders or congenital anomalies reported in the past. On physical examination, a palpable mass about $10 \mathrm{~cm}$ in diameter was identified over the right upper portion of the abdomen. The mass was solid and hard and seemed to be fixed in the peritoneal cavity.

\section{INVESTIGATIONS}

Ultrasonography disclosed a heterogeneous mass measuring $8.8 \times 8.1 \times 11.2 \mathrm{~cm}$ over the right renal fossa with displacement of the kidney (figure 1). $\mathrm{CT}$ of the abdomen showed a large heterogeneous mass with multiple calcifications. Moderate to severe hydronephrosis of the right kidney was identified. In addition, encasement of the IVC with stenosis of the distal segment was found after contrast medium administration (figure $2 \mathrm{~A}, \mathrm{~B}$ ).

\section{TREATMENT}

Surgical intervention with tumour resection was scheduled after surgical risk and tumour resectability evaluation. At surgery, a huge retroperitoneal tumour with anterior deviation of the ascending colon was noted. Complete encasement of the right kidney, associated vessels, ureter and the IVC was found and nephroureterectomy was performed. The narrowed segment of the IVC was noted from outside the tumour capsule continuing to the distal part, which was free of tumour compression (figure 3). The right adrenal gland was removed in case of potential micrometastasis although it was not involved grossly. Finally, the tumour was dissected from the vascular plane of the IVC with minimal residual tumour remaining on the vascular surface.

\section{OUTCOME AND FOLLOW-UP}

After the operation, the patient was sent to our paediatric intensive care unit for monitoring. Pathological examination confirmed the diagnosis of neuroblastoma, stage IV with metastasis to the adrenal gland and the ureter.

After 14 days of observation, progressive recovery was noted and the infant was referred to our paediatric department for subsequent evaluation

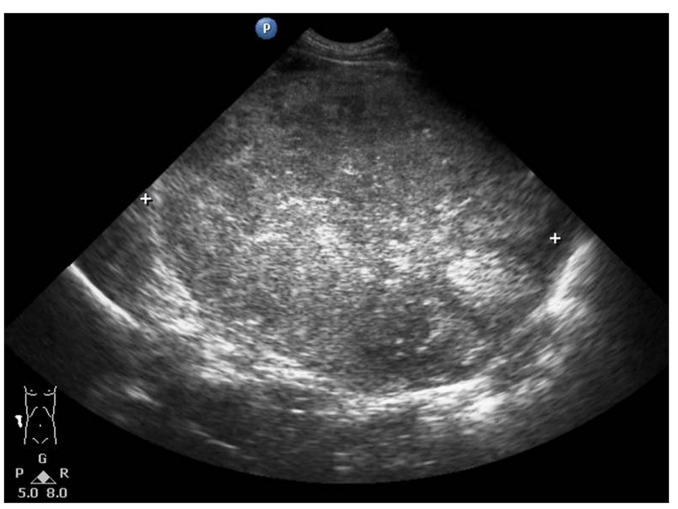

Figure 1 Ultrasonography showing a heterogeneous mass lesion measuring $8.8 \times 8.1 \times 11.2 \mathrm{~cm}$ over the right renal fossa with multiple calcifications. 
Figure 2 (A) Computed tomography showing a large heterogeneous enhancing mass with encasement of the inferior vena cava (arrow). (B) Narrowed segment of the inferior vena cava (arrow).

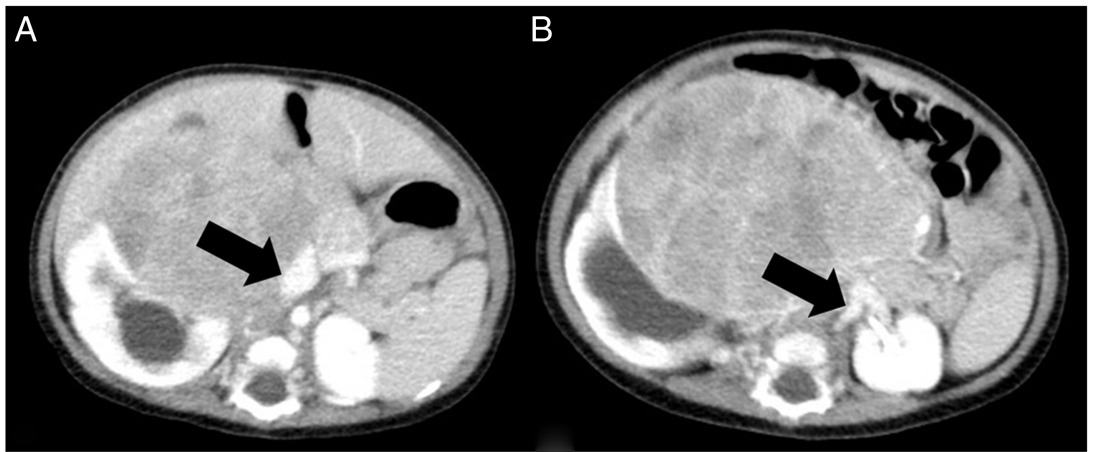

and treatment. One-year follow-up of the patient showed no recurrence and there was no leg oedema.

\section{DISCUSSION}

Stenosis of the IVC is a vascular anomaly that can cause lifethreatening complications if not identified. ${ }^{1}$ This rare vascular defect may be congenital or result from acquired conditions such as tumour invasion, trauma or surgery. ${ }^{2-4}$ In the case of congenital stenosis, the vascular anomalies are characterised by narrowing at the suprarenal level with or without web formation. ${ }^{56}$ Young patients with interrupted IVC or congenital stenosis may present with recurrent deep vein thrombosis and other thromboembolic events, depending on the extent of the stenosis. ${ }^{7}$ However, in our case, the patient was asymptomatic except for a large palpable mass over the right upper quadrant of the abdomen. The intraoperative documentation demonstrated that the narrowed segment of the IVC was at the infrarenal level right below the tumour capsule, although stenosis at the infrarenal level may also occur. ${ }^{1}$ In addition, there was no evidence of external compression, encasement or tumour invasion of this IVC segment. Therefore, due to the clear anatomic site and intraoperative findings, the stenotic lesion may be associated with the neuroblastoma if the potential structural variation of the IVC is not considered. MacDonald ${ }^{8}$ reported four cases of arterial stenosis in neuroblastoma and suggested that the stenosis might be caused by compression by a nearby tumour or be secondary to elongation due to the mass effect. Similarly, the retroperitoneal neuroblastoma in the 5-month-old patient was large enough to

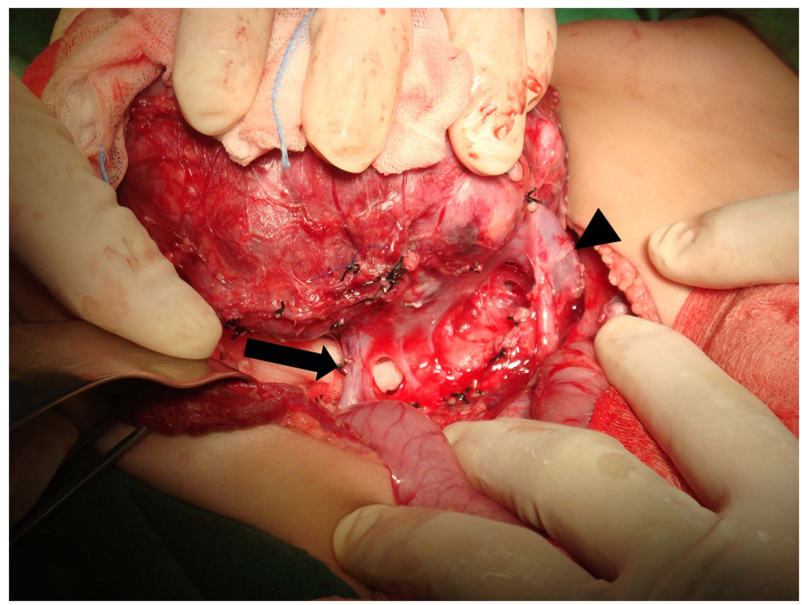

Figure 3 Intraoperative finding showing narrowing of the inferior vena cava (arrow) compared to the normal-sized segment at the suprarenal level (arrow head). exert its bulk effect with occupation and anterior deviation of the peritoneal organs. Therefore, as the IVC was encased in the middle, the elongation and narrowing of the distal segment as the tumour developed was a reasonable finding.

Vascular encasement with stenosis has been described as a characteristic feature of neuroblastoma, reflecting the percolating and invasive nature of this tumour. ${ }^{9}$ This phenomenon is often observed on imaging studies and helps attending physicians differentiate the tumour from Wilms' tumour. However, vascular stenosis due to elongation has not been reported for neuroblastoma, nor has a reason for narrowed vessels not encased or compressed been suggested. Tröbs et al ${ }^{10}$ reported two cases of large retroperitoneal teratomas in infants and described deformation and elongation of large retroperitoneal vessels as one of the anatomical features observed for these tumours. This supports our findings in that retroperitoneal tumours have the potential to grow large enough to affect adjacent structures, causing deformation and elongation of organs and vessels.

Abdominal neuroblastoma with IVC encasement remains a complex surgical challenge. Dissecting the tumour from enclosed vessels prolongs the surgical time and frequently causes vascular injury. This often dissuades paediatric surgeons from performing operations after surgical risk evaluation. Recent studies have shown that children with abdominal neuroblastoma with vascular encasement benefit from complete tumour resection or at least tumour reduction despite intraoperative vascular damage. ${ }^{11}$ In our case, adequate tumour resection seemed to reduce the disease burden in this child, decreasing the extent of vascular narrowing and the possibility of life-threatening thrombo-embolic events. ${ }^{1}$

In cases of vascular stenosis secondary to tumour growth, surgeons should perform complete preoperative evaluation to avoid unfavourable outcomes. However, there are limitations since the narrowed part of the affected vessels may not be easily demonstrated on contrast CT on the background of a huge, heterogeneous neuroblastoma. ${ }^{12}$ Under such conditions, abdominal arteriogram or venogram may be indicated.

\section{Learning points}

Neuroblastoma is the second most common retroperitoneal tumour in children.

- Encasement of vessels in the retroperitoneum is sometimes seen in neuroblastoma.

- Once the tumour has grown large enough and vessels are encased, vascular narrowing can occur due to elongation. 
Contributors J-TL wrote the manuscript, Y-HD reviewed the literature and S-MK corrected the draft.

Competing interests None.

Patient consent Obtained.

Provenance and peer review Not commissioned; externally peer reviewed.

\section{REFERENCES}

1 Koc Z, Oguzkurt L. Interruption or congenital stenosis of the inferior vena cava: prevalence, imaging, and clinical findings. Eur J Radiol 2007;62:257-66.

2 Raju S, Hollis K, Neglen P. Obstructive lesions of the inferior vena cava: clinical features and endovenous treatment. J Vasc Surg 2006;44:820-7.

3 Gayer G, Luboshitz J, Hertz M, et al. Congenital anomalies of the inferior vena cava revealed on CT in patients with deep vein thrombosis. AJR Am J Roentgenol 2003;180:729-32.

4 Zhang L, Yang G, Shen W, et al. Spectrum of the inferior vena cava: MDCT findings. Abdom Imaging 2007;32:495-503.
5 Minniti S, Visentini S, Procacci C. Congenital anomalies of the venae cavae: embryological origin, imaging features and report of three new variants. Eur Radiol 2002:12:2040-55.

6 Okuda K. Membranous obstruction of the inferior vena cava (obliterative hepatocavopathy, Okuda). J Gastroenterol Hepatol 2001;16:1179-83.

7 Vasco PG, Lopez AR, Pineiro ML, et al. Deep venous thrombosis caused by congenital inferior vena cava agenesis and heterozygous factor $\mathrm{V}$ Leiden mutation —a case report. Int J Angiol 2009;18:147-9.

8 Peter MacDonald DCF. Harwood-Nash. Arterial stenosis in neuroblastoma. AJR Am J Roentgenol 1971;112:167-9.

9 Bakody PJ, Stanley P. Vascular stenosis with retroperitoneal rhabdomyosarcoma in a child: case report. Cardiovasc Intervent Radiol 1983;6:131-2.

10 Tröbs R-B, Geyer C, Hirsch W, et al. Surgical anatomy of large retroperitoneal teratomas in infants: report of two cases. Clin Med Case Rep 2008:1:107-11.

11 Warmann SW, Seitz G, Schaefer JF, et al. Vascular encasement as element of risk stratification in abdominal neuroblastoma. Surg Oncol 2011;20:231-5.

12 Bousvaros A, Kirks DR, Grossman H. Imaging of neuroblastoma: an overview. Pediatr Radiol 1986:16:89-106.

Copyright 2014 BMJ Publishing Group. All rights reserved. For permission to reuse any of this content visit http://group.bmj.com/group/rights-licensing/permissions.

BMJ Case Report Fellows may re-use this article for personal use and teaching without any further permission.

Become a Fellow of BMJ Case Reports today and you can:

- Submit as many cases as you like

- Enjoy fast sympathetic peer review and rapid publication of accepted articles

- Access all the published articles

- Re-use any of the published material for personal use and teaching without further permission

For information on Institutional Fellowships contact consortiasales@bmjgroup.com

Visit casereports.bmj.com for more articles like this and to become a Fellow 